\title{
Assessing Productivity Performance Of Regional Electric Cooperatives In The Philippines
}

Ramon C. Posadas, (E-mail: luelco_apo@yahoo.com), University of Santo Tomas, Philippines Emilyn Cabanda, (E-mail: eccabanda@mnl.ust.edu.ph), University of Santo Tomas, Philippines

\begin{abstract}
This paper examines the productivity performance of private electric cooperatives (ECs) in the Philippines. Our sample draws on 15 regions in the Philippines, with a total of 117 cooperatives over the period 1999-2003. Data envelopment analysis (DEA) models are used to calculate productive performance of our panel sample. Our findings suggest that regional electric cooperatives (RECS) are technologically-oriented, yet, show a declining efficiency change of 0.1 percent annually. In this case, the electricity industry across regions may adopt a weighted combination of electricity-based technologies and supported with policies of autonomy without losing the service-oriented culture. Thus, productivity is driven more by technological innovations in the industry than managerial efficiency. This is a new empirical contribution to the electricity productivity literature.
\end{abstract}

\section{INTRODUCTION}

-ny development framework of any country is inextricably linked with the power and energy sector, particularly on electricity. Electricity has been recognized as an indispensable commodity to mobilize all efforts in pushing the worldwide wave of globalization and borderless transactions of sectors. In all indications, electricity is a prime commodity to development. One of the distinct factors of electricity sector is its productivity performance and distribution of electricity service to end users. The study of electricity performance has been acknowledged worldwide (see Pun and Shiu, 2002; Finn and Kittelsen, 1995; Bardadioglu, et al., 1996; Yunos and Hawdon, 1997; Olatuba and Dismukes, 2000) Khumbakan and Hjalmarsson, 1994; Jones, 1990) However, there is a dearth in literature on the productive performance of regional electric cooperatives in the Philippines, except studies of Lavado (2004) and Pacudan and de Guzman (2002). This is the apparent gap in the performance literature that this present research will attempt to address.

In the Philippines, electricity service is a multiple approach. Regional electric cooperatives (RECs) serve the rural areas, and their performance and distribution system is under the supervision, control, policy direction and coordination of the National Electrification Administration (NEA). This is an agency under the Department of Energy (DOE). NEA is responsible for the formulation and implementation of rural electrification laws, policies and regulations as mandated by the Presidential Decree No. 269. Electric Cooperatives found in various regions of the Philippines are all created, and they operate by the virtue of Republic Act 6038 since June 1969 upon the declaration of the national policy on electrification program for the rural areas. As a service sector in an area coverage, regional electric cooperatives are non-profit in nature, with the purpose of sustaining the operations for effective electricity service to its members and clients.

Cognizant of electricity service, the World Bank assessed the EC's productivity performance as well as its distribution system. Results of the assessment reflected to be inefficient and substantial losses with a minimum of 25 percent to a high $45-50$ percent, and most EC's productivity and distribution performance was below standards and low service reliability (World Bank, 1989). In line with this report on EC's unproductive performance, this paper attempts to verify and investigate the recent productivity performance of ECs as they distributed in all 15 regions of 
the Philippines. This present investigation attempts to apply the modern and multidimensional approach to performance evaluation by employing a Data Envelopment Analysis (DEA). This methodology is discussed in detail in the next section. The rest of the paper is organized as follows. Section 2 presents the data sample and methodology of DEA models (DEA-Malmquist and Multi-Stage). Section 3 analyzes all significant findings and conclusions are discussed in Section 4.

\section{DATA AND METHODOLOGY}

\section{Data Sample And Variables}

The distribution of the data sample is shown in Table 1.

Table 1

Regional Electric Cooperatives

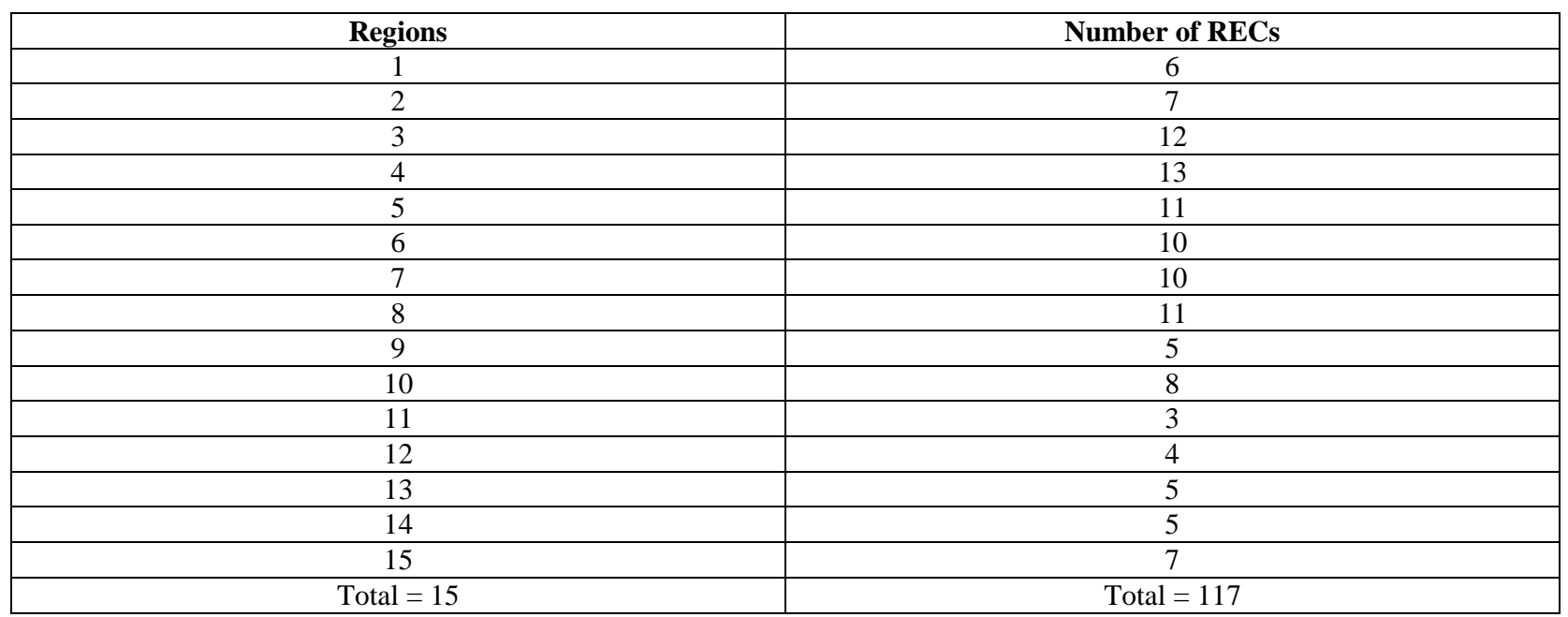

There are four (4) inputs and five (5) outputs selected to evaluate productivity performance of regional cooperatives over the period 1999-2003 and all included in the DEA model. Input variables considered are as follows:

1. Number of employees refers to the total human workforce that are positioned/designated to function and certain tasks be it administrative, managerial and/or members of the rank-in-file.

2. Power Cost refers to the consumer's account that represents cost/price at a point of receipt of electricity purchased for resale.

3. Depreciation expense is a proxy of capital.

4. Administration and General Expenses cover the REC's accounts for salaries, office supplies, outside services employed, property insurance, injuries and damages, employees benefits, pensions, franchise requirements and regulation commission expenses, rents, maintenance of office and general plants, taxes and property, officers allowances and benefits, travel, training association and membership dues and other miscellaneous general expenses.

Outputs are the outcomes, products or characteristics that the REC's management expects. These include: 
1. Total operating revenue represents the total sub-accounts on residential sales, commercial, industrial, sales to public building and facilities, sale to commercial water system and sale for resale.

2. MWH Sales refer to the mega watt hour (MWH) sales that indicate the capability to generate income/revenue and to sustain the financial needs of the REC.

3. MGH generated/purchased refers to the mega watt hour/electricity purchased for resale to consumers.

4. Number of consumers refers to the total population that uses electricity and classified as residential, commercial, Barangay Power Association (BAPA), industrial, public building, street lights and commercial water systems.

5. Total assets represent the total investment of the utility plant, other property and investments, cash and temporary cash investments, notes and accounts receivable, materials and supplies, other current and accrued assets such as prepayments and differed debits. Therefore, this variable is treated as an output since they maximizes stockholder's wealth as relate to the "cooperative" nature of the organization.

The DEA models are limited only on the above input and output mixes. The selection of variables is discretionary and also based on previous productivity literature (see Pun and Shiu, 2002; Finn and Kittelsen, 1995; Bardadioglu, et al., 1996; Yunos and Hawdon, 1997; Olatuba and Dismukes, 2000; Khumbakan and Hjalmarsson, 1994; Jones, 1990; Lavado, 2004;Pacudan and de Guzman, 2002). These data variables are extracted from published annual reports of National Electrification Administration and audited annual financial reports of RECs. Other data sources came from the following Philippine agencies: Energy Regulatory Commission (ERC), Philippine Rural Electric Cooperatives Association Office, and the Department of Energy.

\section{DEA-Malmquist}

DEA is a linear programming model that uses data on multiple input and output variables of a group of firms to construct a piece-wise linear surface over the data points. It was first applied by Charnes et al. (1978) in the U.S. at a non-profit sector. Productivity consists of measuring the change in ratio of outputs over inputs used in a production process over time. The DEA-Malmquist, which is an indicator of productivity, is an approach that uses panel data to estimate changes in total factor productivity (TFPCH). Fare et al. (1994) provided the output-orientated Malmquist productivity index change, using both time period references as stated in Equation (1):

$$
M_{o}\left(x^{t+1}, y^{t+1}, x^{t}, y^{t}\right)=\frac{D_{0}^{t+1}\left(x^{t+1}, y^{t+1}\right)}{D_{0}^{t}\left(x^{t}, y^{t}\right)} \times\left[\frac{D_{0}^{t}\left(x^{t+1}, y^{t+1}\right)}{D_{0}^{t+1}\left(x^{t+1}, y^{t+1}\right)} \times \frac{D_{0}^{t}\left(x^{t}, y^{t}\right)}{D_{0}^{t+1}\left(x^{t}, y^{t}\right)}\right]^{1 / 2}
$$

where $\left(M_{0}\right)$ is the Malmquist productivity index from period $\mathrm{t}$ (benchmark) to period $\mathrm{t}+1$ relative to input-output mixes under the constant returns to scale assumption. The equation on the right is a ratio of the distance of each point to serve as a benchmark to compare a certain bundle of input $(\mathrm{x})$ and output (y) used in the production process. To calculate these distance functions, it is important to solve several linear programming problems, with the aid of DEA method.

The striking characteristic of the Malmquist index is its ability to decompose the total factor productivity into technical efficiency change (EFFCH) (catching-up effect) and technical change (TECHCH) (or technological progress). Again Fare et al. (1994, p. 71) expressed this decomposition as: 
The Malmquist index is an index of the geometric mean of TFP index from period $t$ to $t+1$. When the index is greater $(>1)$ than one, this indicates an improved productivity and lower than one $(<)$ is a decline in productivity and finally, equal to one means no change (constant) in productivity. The Malmquist index is derived with the help of an available computer program called Data Envelopment Analysis Program (DEAP) Version 2.1. (Coelli, 1996).

\section{Multi-Stage DEA Model}

Efficiency can be characterized with an input orientation under the variable returns to scale, when all units are believed to be not efficient and operating not at optimal scale due to organizational constraints such as size, location, age, etc. The input-orientation assumption is used for the input minimization from a given output level of regional cooperatives expressed as:

Subject to:

\section{Minimize E}

$\mathrm{WX} \leq \mathrm{EX}_{\mathrm{o}}$

$\mathrm{WY} \geq \mathrm{Y}_{\mathrm{o}}$

$\mathrm{W} \geq 0$

where $\mathrm{X}$ and $\mathrm{Y}$ are input and output matrices, respectively: $\mathrm{X}_{\mathrm{o}}$ and $\mathrm{Y}_{\mathrm{o}}$ are input and output vectors, respectively for the REC being evaluated; $\mathrm{W}$ is a vector representing the weights (\%) of inputs and outputs of RECs used in constructing a composite Decision-Making Unit (DMU) under evaluation. Lastly, E is the efficiency index. If the optional solution of the above linear program has an objective function value of $E=1$, then it implies that REC is relatively efficient. If the value of the objective function is less than $1(\mathrm{E}<1)$, then it means that a REC is inefficient. Input and output slacks $(\%)$ are calculated to realize how much improvement is needed for each variable used. Input slacks refer to input excess if there is a surplus use of input resources and calls for a reduction for a DMU to be efficient. Output slacks mean deficit and further increase is needed to reach the efficient frontier. Again, slacks are calculated by means of a computer software called DEAP v2.1 (Coelli, 1996).

\section{EMPIRICAL FINDINGS}

Table 2 shows all regional electric cooperatives and their respective ranks and Malmquist indices.

Evidently, all regions' TECHCH scores show an index value greater than one, with a high of 15.8 percent growth per year. This result implies the positive injection and adoption of technology for the productive performance of these RECs over the time period. The TFP experienced a positive growth of 15.7 percent annually. Thus, regional electric cooperatives are showing a better productive performance that attributed more from positive innovations. Logically, all regions tend to acquire and adopt more technological innovations or processes. Perhaps all RECs help each other, considering their close geographic proximity; likewise, they may have unity, cooperation, and similarities when it comes to technological advancements. 
Table 2

Malmquist Index Summary of Means and Ranks of Regional Electric Cooperatives

\begin{tabular}{|c|c|c|c|c|c|c|}
\hline REGIONS & Rank & EFFCH & Rank & TECHCH & Rank & TFPCH \\
\hline 1 & $\mathbf{3}$ & 1.000 & $\mathbf{3}$ & 1.171 & $\mathbf{6}$ & 1.171 \\
\hline 2 & $\mathbf{3}$ & 1.000 & $\mathbf{4}$ & 1.121 & $\mathbf{1 1}$ & 1.122 \\
\hline 3 & $\mathbf{3}$ & 1.000 & $\mathbf{5}$ & 1.235 & $\mathbf{1}$ & 1.235 \\
\hline 4 & $\mathbf{3}$ & 1.000 & $\mathbf{6}$ & 1.193 & $\mathbf{2}$ & 1.193 \\
\hline 5 & $\mathbf{1}$ & 1.014 & $\mathbf{1}$ & 1.170 & $\mathbf{3}$ & 1.187 \\
\hline 6 & $\mathbf{5}$ & 0.982 & $\mathbf{1 4}$ & 1.139 & $\mathbf{1 2}$ & 1.118 \\
\hline 7 & $\mathbf{4}$ & 0.999 & $\mathbf{1 2}$ & 1.041 & $\mathbf{1 3}$ & 1.039 \\
\hline 8 & $\mathbf{5}$ & 0.992 & $\mathbf{1 3}$ & 1.160 & $\mathbf{8}$ & 1.151 \\
\hline 9 & $\mathbf{3}$ & 1.000 & $\mathbf{7}$ & 1.157 & $\mathbf{7}$ & 1.157 \\
\hline 10 & $\mathbf{3}$ & 1.000 & $\mathbf{8}$ & 1.137 & $\mathbf{1 0}$ & 1.137 \\
\hline 11 & $\mathbf{3}$ & 1.000 & $\mathbf{9}$ & 1.174 & $\mathbf{5}$ & 1.174 \\
\hline 12 & $\mathbf{3}$ & 1.000 & $\mathbf{1 0}$ & 1.183 & $\mathbf{4}$ & 1.183 \\
\hline ARMM & $\mathbf{3}$ & 1.000 & $\mathbf{1 0}$ & 1.183 & $\mathbf{4}$ & 1.183 \\
\hline CAR & $\mathbf{2}$ & 1.001 & $\mathbf{2}$ & 1.172 & $\mathbf{5}$ & 1.174 \\
\hline CARAGA & $\mathbf{3}$ & 1.000 & $\mathbf{1 1}$ & 1.142 & $\mathbf{9}$ & 1.142 \\
\hline Geometric Mean & & $\mathbf{0 . 9 9 9}$ & & $\mathbf{1 . 1 5 8}$ & & $\mathbf{1 . 1 5 7}$ \\
\hline
\end{tabular}

Region 3 with a remarkable TFP growth of 23.5 percent appears to be the most productive relative to its peers due to its high innovation. TFP growth ranged from 3.9-23.5 percent per year: an indication of a positive productive performance of all regions. As indicated in Table 2, all regions managed to attain index values greater than one. In short, TFP growth can be equated to high technological innovation as evident in the sample regions.

For efficiency performance, a deterioration of 0.1 percent is observed, which was due to scale inefficiency and thus, failed to reach the efficient frontier. It implies that the managerial efficiency performance of these regions needs further improvement to attain the standard 100 percent efficiency. The lowest catching-up effects are apparent in Regions 6, 7 and 8: an indication of the failure to maximize service-oriented outputs out of their given resources.

Table 3 and Figure 1 exhibit the Malmquist index summary of RECs annual mean over 1999-2003 period.

Table 3

Malmquist Index Summary of Annual Means of RECs, 1999-2003

\begin{tabular}{|c|c|c|c|}
\hline Year & EFFCH & TECHCH & TFPCH \\
\hline 1999 & 0.999 & 1.806 & 1.805 \\
\hline 2000 & 0.997 & 0.969 & 0.966 \\
\hline 2001 & 1.007 & 1.004 & 1.011 \\
\hline 2002 & 0.994 & 1.022 & 1.016 \\
\hline Mean & 0.999 & 1.158 & 1.157 \\
\hline
\end{tabular}

Note: 1999 indices are not defined; it begins with year 2 


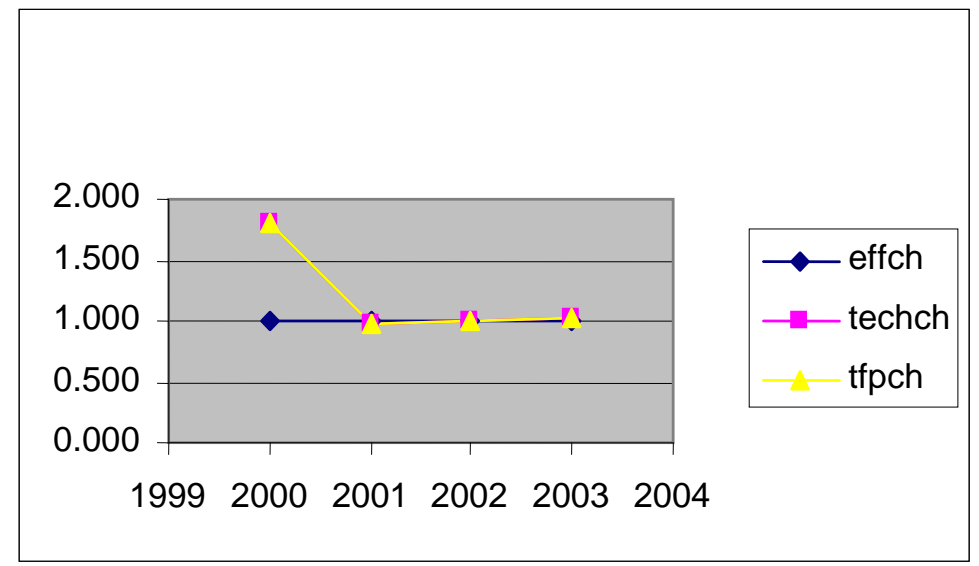

Figure 1: Malmquist Index Summary of Annual Means of Regional Electric Cooperatives

Table 3 and Figure 1 show technical efficiency change, technological change and total factor productivity of all regions from 1999-2003. It is observed, that there was a decline in TFP growth from 1.805 in 2000 to 1.016 in 2003. Findings are indicative of the productive performance of RECs during the period, except in 2001 in which they failed to move towards the world frontier of productivity. In 2000, RECs were most productive which was due to technological progress. The abrupt fall in 2001 when RECs performed lower than the best-practice frontier may have caused by other factors, which are not included in the study. Several factors may have caused this decline such as rapid expansion of installed capacity and perhaps other macroeconomic factors that may have caused the decrease of productivity in that year.

On average, TFP growth is caused by high technological advancements than managerial efficiency over the period. Regional electric cooperatives have managed to tap and adopt new electricity technology, equipment, and processes that have resulted in high productivity growth. In short, productivity is associated with technological innovations. However, over the period, some RECs experienced deterioration in their efficiency performance due to managerial inefficiencies of utilizing input resources.

Table 4

\begin{tabular}{|c|c|c|c|c|c|c|c|c|c|}
\hline \multicolumn{10}{|c|}{ INPUT AND OUTPUT SLACKS (\%) Summary, 2003} \\
\hline \multirow[b]{3}{*}{ REGION } & \multicolumn{4}{|c|}{ INPUT } & \multicolumn{5}{|c|}{ OUTPUT } \\
\hline & Number & Power & Depreciation & $\begin{array}{l}\text { Admin } \\
\&\end{array}$ & $\begin{array}{c}\text { Total } \\
\text { Operating } \\
\end{array}$ & MWH & MWH & Number of & Total \\
\hline & $\begin{array}{c}\text { of } \\
\text { Employees } \\
\end{array}$ & Cost & expense & $\begin{array}{c}\text { General } \\
\text { Expenses }\end{array}$ & Revenue & Purchased & Sales & Consumers & Assets \\
\hline 1 & - & - & - & - & - & - & - & - & - \\
\hline 2 & - & - & - & - & - & - & - & - & - \\
\hline 3 & - & - & - & - & - & - & - & - & - \\
\hline 4 & - & - & - & - & - & - & - & - & - \\
\hline 5 & - & - & - & - & - & - & - & - & - \\
\hline 6 & - & - & 9 & - & - & 30 & 33 & 14 & 1 \\
\hline 7 & - & - & - & - & - & 15 & 7 & - & 15 \\
\hline 8 & - & - & - & - & - & 14 & 15 & - & 9 \\
\hline 9 & - & - & - & - & - & - & - & - & - \\
\hline 10 & - & - & - & - & - & - & - & - & - \\
\hline 11 & - & - & - & - & - & - & - & - & - \\
\hline 12 & - & - & - & - & - & - & - & - & - \\
\hline 13 & - & - & - & - & - & - & - & - & - \\
\hline 14 & - & - & 26 & 14 & - & 44 & 36 & - & - \\
\hline 15 & - & - & - & - & - & - & - & - & - \\
\hline
\end{tabular}

- none or zero slack 
Table 4 reflects the input-output slacks of the 15 regional groupings of electric cooperatives. For a region to be efficient a zero slack must be achieved in any of the input and output variables. As shown in Table 4, majority (11) of the regions are efficient in achieving productivity change. On one hand, regions 6 and 14 fell short to satisfy zero slack in the input variables on depreciation expenses as they posted 9 percent (Region 6) and 26 percent (Region 14) excesses on capital in their electric cooperatives. Region 14 needs to reduce by 14 percent in its other administration and general expense to be efficient. Meanwhile, the output slacks reflect a number of regions with deficiencies in the total MWH purchased wherein Region 6 pegged at 30 percent; Region 7 with 15 percent; Region 8 with 14 percent; and Region 14 posted the biggest deficiency with 44 percent. Similarly, the same regions posted deficiencies in MWH sales. Only Region 6 showed a 14 percent deficiency in total number of consumers, implying to increase its consumers to attain efficiency. In the total assets, Region 6 (1\%); Region 7 (15\%) and Region 8 (9\%) posted deficiencies, respectively. Results indicate that these regions failed in their efficient performance to attain the zero slack level of output for productivity change. However, majority of the regions of ECs satisfy the ideal (zero) slack level, especially in labor, power cost, and operating revenue. Therefore, these regions are considered efficient in the utilization of their input resources.

Table 5

\begin{tabular}{|c|c|}
\hline \multicolumn{2}{|c|}{ SUMMARY OF PEERS (2003) } \\
\hline Region & Peers \\
\hline 1 & 1 \\
\hline 2 & 2 \\
\hline 3 & 3 \\
\hline 4 & 4 \\
\hline 5 & 5 \\
\hline 6 & $11,12,1$ \\
\hline 7 & $10,1,3,11,5$ \\
\hline 8 & $3,11,10,1,12$ \\
\hline 9 & 9 \\
\hline 10 & 10 \\
\hline 11 & 11 \\
\hline 12 & 12 \\
\hline 13 & 13 \\
\hline 14 & $13,12,10,11$ \\
\hline 15 & 15 \\
\hline & \\
\hline & \\
\hline
\end{tabular}

Table 5 identifies the regional peers for benchmarking performance. Using input-oriented model, it is observed that 11 regions (Region 1, 2, 3, 4, 5, 9, 10,11,12,13 \& 15) are considered a peer to itself since they are found efficient. These regions have utilized their unique input-output mixes that make them efficient, therefore, they do not need to benchmark performance of other regions. Results imply that these regions managed to utilize their inputs wisely to be at par with the best-practice standard. This is an indication that there is development and progress in these regions. However, there are four (4) regions (Region 6, 7, $8 \& 14$ ) that posted input resource excesses and deficits in their output resources. The results manifest that these regions were inefficient and therefore need to benchmark the efficient regions to improve their performance.

\section{CONCLUSIONS}

This paper examines the productivity performance of 15 regional electric cooperatives in the Philippines, using DEA models. Findings suggest that the TFP growth of all regions is due more to technological innovations. Regional ECs all throughout the country have acquired innovative technology and processes, enabling them to raise their productivity level to 15.7 percent growth annually. On average, efficiency change has declined to 0.1 percent, implying the need to improve electricity service performance across regions. 
There are two important policy implications derived in this paper: (1) Since TFP growth is equated with technological progress, regional ECs are still challenged on how to sustain this productivity growth in the long run; perhaps, they may continuously strive for on-going research and discovery on electricity-based innovations. (2) The deterioration in managerial efficiency calls for the careful review of available resources to avoid further waste and to establish a balance with their target outputs. Output deficit and input excesses must be addressed with caution by the REC's management toward the improvement of their organizational performance. Therefore, the DEA models and findings here shall serve only as guidelines for the REC's management and shall be taken with proper caution. This paper shows how DEA models are helpful in the assessment of electricity productivity performance. Apparently, the models have their own limitations that can be strengthened and complemented by using other econometric models. However, due to this acknowledged limitation of the present research, this area can be addressed by future investigation.

\section{ACKNOWLEDGMENTS}

The Graduate School of the University of Santo Tomas, Manila, Philippines is hereby acknowledged for the research support provided. This research derives from the Ph.D. dissertation of the primary author. We are also grateful to Tim Coelli's DEAP (2.1) for the computer program. The authors are lone responsible for other remaining errors and not of the institution they represent.

\section{REFERENCES}

1. Bagdadioglu, Necmiddin et al. (1996). Efficiency and ownership in Electricity Distribution: In non-parametric model of Turkish Experience. Energy Economics, 18, 1 - 23.

2. Coelli, Tim; D.S. Rav; and George Battese. (1998). An Introduction to Efficiency and Productivity Analysis. U.S.A.: Kiluwen Academic Publishers.

3. Coelli, Tim (1997) A Guide to DEAP Version 2.1; A Data Envelopment Analysis (Computer) Program. Working Paper Center for Efficiency and Productivity Analysis. Department of Economics University of New England.

4. Charnes, A., et al (1978). Evaluating Programs and Managerial Efficiency. An Application of data envelopment Analysis to program follow through Management Science 27 (6): 668-697.

5. Chen, Tser-Yieth. (2001). An Estimation of X-inefficiency in Taiwan's Banks. Applied Financial Economics 11: 237-242.

6. Dhawan, Rajeev. 2001. Firm size and productivity differential: theory and evidence from a panel of US firms. Journal of Economic Behavior and Organization, 44, 269-293.

7. Fare, Rolf et al (1994) Productivity Growth, Technical Progress and efficiency designed in Industrialized Countries. The American Economic Review 84: 66-83.

8. Finn, Forsund R. and Sverre A.C. Kittelsen. (1998). Productivity Development of Norwegian Electricity Distribution Utilities. Resource and Energy Economics 20 (1998) 207-224, Elsevier Science B.V.

9. Jones, Thomas- Weyman G. (1991). Productive Efficiency in a Regulated Industry - The Area Electricity Boards of England and Wales. Energy of Economics, E Butter worthy Heinemann Ltd.

10. Kumbhakar, Subal C. and Lemmart Hjalmarsson. (1997). Relative Performance of Public and private ownership under yard stick competition: Electricity Retail Distribution, EUROPEAN Economic Review 42.

11. Lavado, Rousselle (2004). Benchmarking the efficiency of electric cooperatives in the Philippines. In Ali Emrouznejad and Victor Podinovski, eds. Data Enevelopment Analysis and Performance Management. Aston University, UK.

12. N E A. (2003). Electric Cooperatives Transformation Volume 1, Summary Finding, February.

13. N E A. (2003). Technical Assistance for Institutional Management Transformation of NEA and ECs: Part II EC Transformation. The PIMA Foundation, May.

14. Pacudan, Romeo and E. De Guzman. (2002). Impact of Energy Efficiency Policy to Productive Efficiency of Electricity Distribution Industry in the Philippines. Energy Economics 24: 41-54

15. Pun-Lee Lam and Alic Shiu. (2002). A Data Envelopment Analysis of the Efficiency of China's Thermal Power Generation. Utilities Policy 10: 75-83.

16. World Bank. (1993). The World Bank’s Role in the Electric Power Sector: Policies for Effective Institutional Regulatory and Financial Reform, WB. Washington D.C.

17. Yumos, Jawa Luddin Mohd and David Hawdon. (1997). The Efficiency of the National Electricity Board in Malaysia: An Inter Country Comparison using DEA. Energy Economics. 